\title{
Fatigue Life Prediction of Aircraft Engine Bracket
}

\section{${ }^{1}$ Nerannagari Maruthi, ${ }^{2}$ C. Mohan Naidu}

${ }^{1}$ M.Tech Scholar, Department of Mechanical Engineering, SKD Engineering College, Gooty, Andhra Pradesh, India

${ }^{2}$ M.Tech, Associate Professor, HOD of Mechanical Engineering Department, SKD Engineering College, Gooty, Andhra Pradesh, India

\section{ABSTRACT}

The purpose of this project is to optimize the design, dimensions along with changing in material of the bracket structure to ensure the structural fatigue life increase along with reduction in stress and displacement of the component. Optimization study of components gives a great opportunity for material saving which leads to save cost and man power. The major bracket design parameters were explained in detail and the bracket configuration has been described. Different types of loads acting on the aircrafts bracket are determined and the moments, displacements, etc., are also determined. The bracket structure was also explained and functions of each component and their arrangement are also studied. The methodology of finite element method and the detailed description about various FEM tools have been studied and implemented in this work. The procedure of finite element method was followed to analyse the model. The analysing part of this project is done using CAE tool package and the results were discussed. In this Project, we designed Aircraft engine bracket using CATIA V5 and carried out linear static analysis using MSC Software. For Pre-Processing used MSC PATRAN and MSC NASTRAN for solving followed by Fatigue calculations.

Keywords : PATRAN, Ailerons, rolling motion, Fuselage, Turbofan Engine, Turbojet Engine, Turboprop Engine

\section{INTRODUCTION}

\section{Introduction to Aircraft}

Aircraft is a machine which is supported for flight in the air by buoyancy or by the dynamic action on its surfaces. The airframe is the basic structure of an aircraft and is designed to withstand all aerodynamic forces, as well as the stresses imposed by the weight of the fuel, crew, and payload. In an aircraft, there are 4 parts namely Fuselage, wing, empennage and landing gear system. Forces acting on Aircraft are Thrust, Drag, Lift and Gravity. Control surfaces are changing the attitude of Aircraft during flying. The main control surfaces are Ailerons (rolling motion),
Elevator (pitching motion) and Rudder (yawing motion).

\section{Aircraft Working Principle}

The aircrafts are mainly working on the principle of Bernoulli's theorem and Newton laws of motion which deal with the motion of air and the forces acting on a body moving relative to that air. A propulsion system is a machine that produces thrust to push an object forward. On airplanes, thrust is usually generated through some application of Newton law of action and reaction. A gas, or working fluid, is accelerated by the engine, and the reaction to this acceleration produces a force on the engine. 


\section{METHODS AND MATERIAL}

\section{Aircraft Parts}

The airframe of an aircraft consists of the following major units:

1. Fuselage

2. Wings

3. Stabilizers

4. Flight controls surfaces

5. Landing gear

6. Empennage

\section{Fuselage}

The fuselage is the main structure, or body, of the aircraft. It provides space for personnel, cargo, controls, and most of the accessories. The power plant, wings, stabilizers, and landing gear are attached to it. It has a sharp or rounded nose with sleek and tapered body so that the air can flow smoothly around it.There are two general types of fuselage construction,

1. Welded steel truss

2. Monocoque designs.

\section{Wings}

Wings develop the major portion of the lift of a heavier-than-airaircraft. Wing structures carry some of the heavier loads found in the aircraft structure. The particular design of a wing depends on many factors, such as the size, weight, speed, rate of climb, and use of the aircraft. The wing must be constructed so that it holds its aerodynamics shape under the extreme stresses of combat manoeuvres or wing loading.

Wing construction is similar in most modern aircraft. In its simplest form, the wing is a framework made up of spars and ribs and covered with metal. The construction of an aircraft wing is shown in figure.

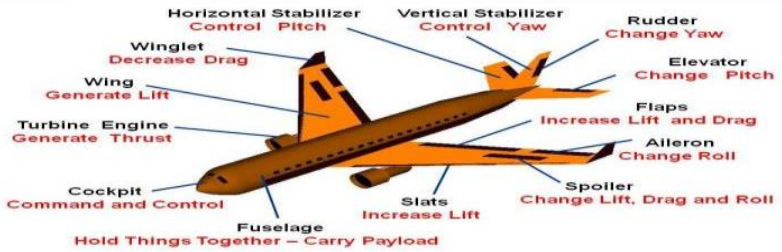

Fig 1. Parts of Aircraft

\section{Stabilizer}

The stabilizing surfaces of an aircraft consist of vertical and horizontal air foils. They are called the vertical stabilizer (or fin) and horizontal stabilizer. These two air foils, along with the rudderandelevators, form the tail section. For inspection and maintenance purposes, the entire tail section is considered a single unit called the empennage.

\section{Landing gear}

The landing gear system is placed in bottom surface of Aircraft. It carries the weight of an aircraft during landing and taxing conditions. It is one of the complicated part in an Aircraft. There are 3 types of landing gear apply to the surfaces are water, earthed and snow or ice (skis type). During landing impact load absorbed by shock absorber (vertical load), when tire touches the ground drag load generated and side load due to the aircraft body.

\section{Empennage}

Commonly known as the "tail section," the empennage includes the entire tail group which consists of fixed surfaces such as the vertical fin or stabilizer and the horizontal stabilizer. The movable surfaces including the rudder and rudder trim tabs, as well as the elevator and elevator trim tabs. These movable surfaces are used by the pilot to control the horizontal rotation (yaw) and the vertical rotation (pitch) of the airplane. 


\section{Aircraft Engines}

\section{Introduction}

Aircraft engine means an engine that is used for propelling aircraft. A propulsion system is a machine that produces thrust to push an object forward. On airplanes and spacecraft, thrust is generated through some application of Newton's third law of action and reaction. A gas, or working fluid, is accelerated by the engine, and the reaction to this acceleration produces a force on the engine.

\section{Types of Engines}

1. Internal Combustion (Piston) Engines

2. Types of Turbine Engines

3. Turbojet Engines

4. Turbofan

5. Turboprop Engines

6. Afterburning Engines

7. Ramjet and Scramjet Engines

8. Ion Engines

\section{Internal Combustion Engine}

Airplanes used internal combustion engines to turn propellers, which generate thrust. As the name implies, the combustion process of an internal combustion engine takes place in an enclosed cylinder where chemical energy is converted to mechanical energy. Inside the cylinder is a moving piston which compresses a mixture of fuel and air before combustion and is then forced back down the cylinder following combustion. On the power stroke the piston turns a crankshaft, which converts the linear (up and down) motion of the piston into circular motion. The turning crankshaft is then used to turn the aircraft propeller. The motion of the piston is repeated in a thermodynamic cycle called the Otto Cycle.

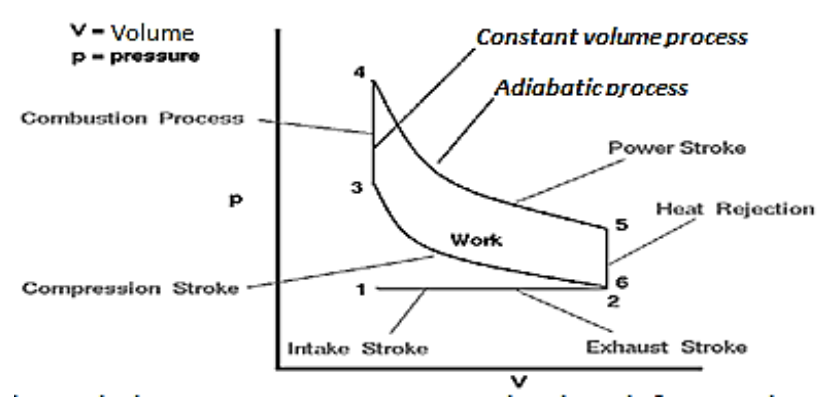

Fig 2. P-V Diagram of Ideal Otto Cycle

Ideal Otto Cycle compression, or forcing more air into the cylinder (supercharging) are all ways this can be accomplished. With aircraft engines these changes cause some problems. Increasing the number or size of the cylinders adds weight to the engine and creates more heat that must be dissipated. Some aircraft engines are air-cooled to save weight, and radial arrangements of cylinders as shown below allow for more cooling but increase drag. Others are water cooled, requiring the additional weight of a radiator and water. Raising the pressure in the cylinders creates more heat, stresses metal, and requires special fuel to prevent knocking. Engineers are always trying to maximize the balance between the positive and negative forces in any processes. Also note that the Otto cycle to the left is labelled "ideal." In actual operation, gasoline engines are in the range of 30 percent efficient because gases don't burn instantly at constant volume, there are losses due to friction, and much of the heat generated goes to waste in the radiator and exhaust rather than to power.

\section{Turbine Engines}

In turbine engines, air is drawn in and compressed, fuel is added and burned, and the hot gases expand out the rear of the engine, pushing the aircraft forward. Some of these exhaust gases turn a turbine, which drives the compressor. A number of different types of gas turbine engines have been developed for 
use depending upon the specific needs of a particular type of aircraft.

\section{a. Turbojets}

All the thrust of these engines comes through the turbine and nozzle, which is called the core of the engine. These are what people commonly refer to as jet engines.

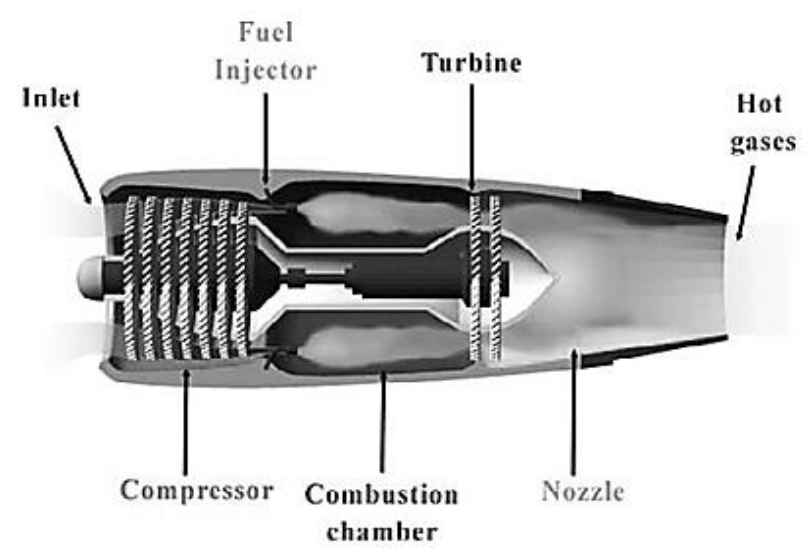

Fig 3. Cutaway view of Turbojet Engine

The turbojet engine, developed for aircraft in the years prior to World War II, was a departure in thinking from the standard piston engine. Instead of burning fuel in a confined space that is dependent upon precise timing of ignition, the turbojet engine is essentially an open tube that burns fuel continuously. According to Newton's Third Law, as hot gases expand out from the rear of the engine, the engine is accelerated in the opposite direction. The engine consists of three main parts, the compressor, the burner, and the tur- bine, along with the inlet, shaft, and nozzle, as shown above.

\section{b. Turbofans}

These engines have a central engine core that uses about 10 percent of the intake air while a large turbine powered fan pushes about 90 percent of the intake air around.

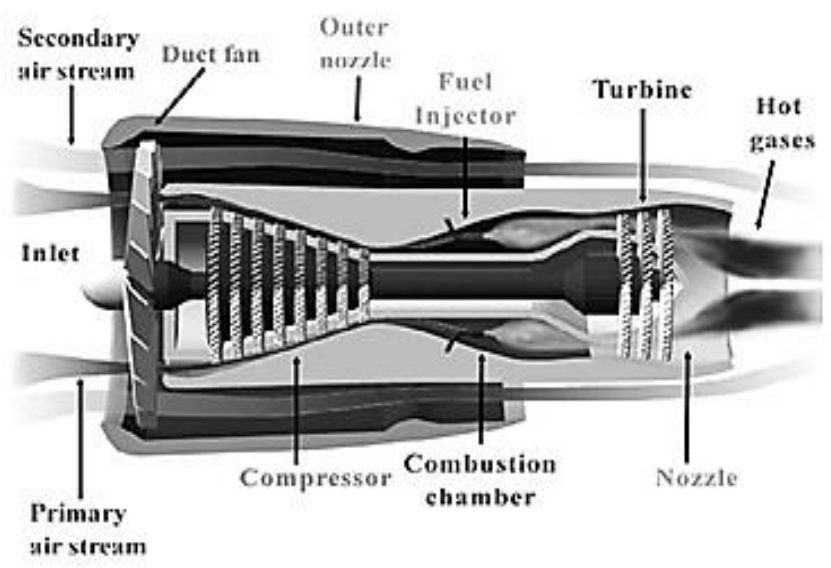

Fig 4. Cutaway view of Turbofan Engine the outside of the core to produce most of the thrust.

These are used on most commercial passenger aircraft because they make more thrust for every pound of fuel burned in the core.

\section{c. Turboprop Engines}

Turboprop engines are aircraft engines with a turbine hot section turning a propeller

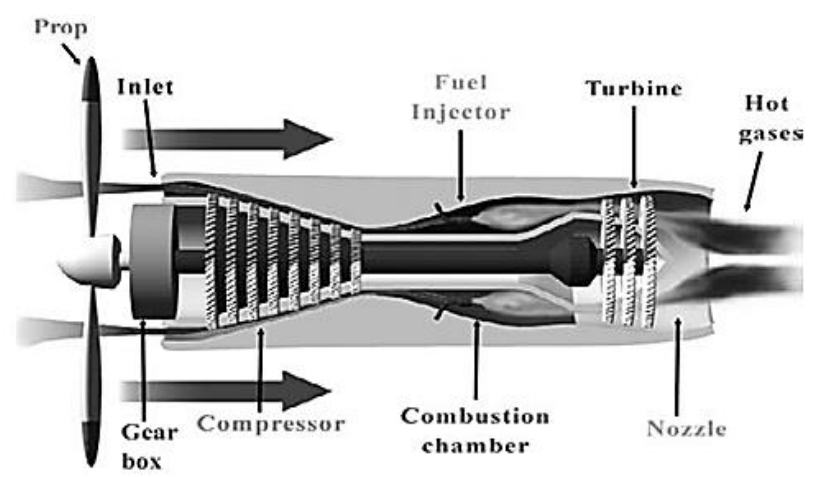

Fig 5. Cutaway view of Turboprop Engine

or rotor. The guts of a turboprop are the same as a jet engine. Turboprop engines allow are used in aircraft similar to those using piston engines, just a few noches bigger and faster. Turboprop engines are used in single, twin and even four engine aircraft like the C-130 Hercules.

\section{d. Afterburning Turbojets}

Afterburners are used only on supersonic fighter aircraft and only for short 


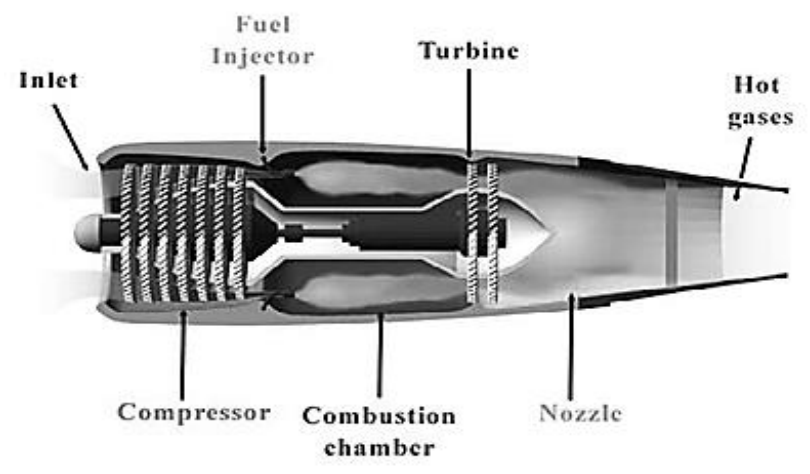

Fig 6. Cutaway view of after burning Turbojets Engine periods of time.

Fuel is injected into the hot exhaust stream to produce additional thrust, allowing for high speed at a cost of high fuel consumption.

\section{Additive Manufacturing}

Additive Manufacturing refers to a process by which digital 3D design data is used to build up a component in layers by depositing material. The term "3D printing" is increasingly used as a synonym for Additive Manufacturing. However, the latter is more accurate in that it describes a professional production technique which is clearly distinguished from conventional methods of material removal. Instead of milling a workpiece from solid block, for example, Additive Manufacturing builds up components layer by layer using materials which are available in fine powder form. A range of different metals, plastics and composite materials may be used.

\section{Working Principle}

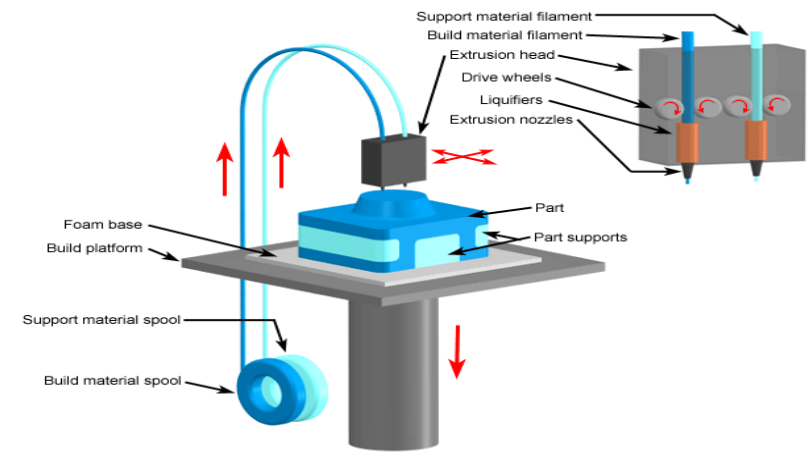

Fig 7. Working principle of 3D printing
The system starts by applying a thin layer of the powder material to the building platform. A powerful laser beam then fuses the powder at exactly the points defined by the computer-generated component design data. The platform is then lowered, and another layer of powder is applied. Once again the material is fused so as to bond with the layer below at the predefined points. Depending on the material used, components can be manufactured using stereo lithography, laser sintering or 3D printing.

\section{Additive Manufacturing (AM) Applications in Aircraft}

AM applications in aerospace include turbine engine blades, heat exchangers, pumps, structural brackets and a fuel nozzle. Here, metal AM may be effectively applied for novel designs as well in the Maintenance, Repair and Overhaul (MRO). The aerospace specific applications involve rapid and large fluctuations in thermal and mechanical conditions. Therefore, resistance to crack initiation and propagation and resistance to creep are crucial for aerospace applications. The benefits of metal Additive Manufacturing are especially suitable to aerospace, with increased demand on fuel efficiency, greenhouse emissions and buy-to-fly ratios.

\section{Materials used in Additive Manufacturing}

The following materials are commonly used for AM in aircraft:
1. Ti-6Al-4V
2. $\mathrm{Co}-28 \mathrm{Cr}-6 \mathrm{Mo}$
3. Nickel-based alloys
4. Aluminum-based alloys
5. Stainless Steel alloys 
Additive Manufacturing provides an opportunity for production with difficult to machine materials, such as Titanium and nickel based alloys. However, Selective Laser Melting and Electron Beam Melting are powder-bed fusion technologies and traditionally powder is used very little in the aerospace industry. Therefore, maintaining a high quality standard proves difficult, as the powder material is one of the main factors to consider when high quality standards are important.

\section{Aircraft Bracket}

Brackets are connector type elements widely used as structural supports to carry hydraulic and electrical lines used in engines, wings and landing gear links. Failure of brackets may lead to the catastrophic failure of the whole structure.

Bracket is a small fitting or support used to attach system parts as duct, bundle, cable, and blanket keeping them in the intended positions. Generally, the brackets are made from steel sheet strip slit and are cut to size before configured to the required shape by bending operation. The brackets are heattreated to obtain the desired surface properties.

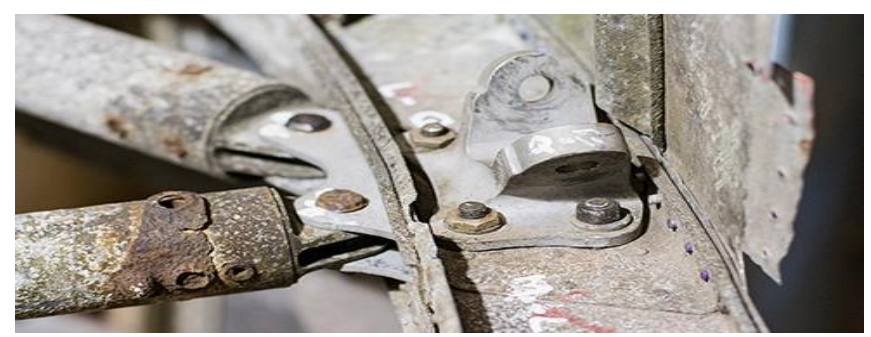

Fig 8. Aircraft Bracket

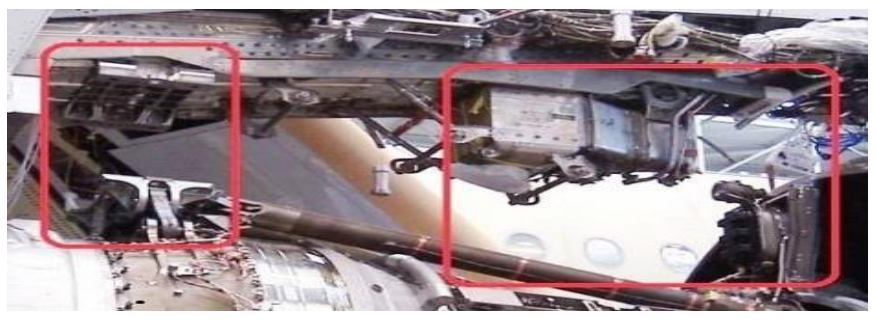

Fig 9. Location of bracket in aircraft engine

\section{Bracket Design Requirements}

The brackets are to be designed such that they will not damage system, structure and insulation brackets during the life span of aircraft. Their weight shall be minimized asmuch as possible thus reducing the overall aircraft weight leading to indirect cost savings. Brackets are designed for their intended use within the operating temperature of the aircraft. The unique feature of the brackets is that they shall be easy to install with a quick-fix mechanism by one technician, thus saving phenomenal time for the installation and disassembly. The number of feature elements constituting the brackets shall be minimized optimally.

\section{Materials Selection Criteria}

Materials selection is quite frequently a compromise involving various considerations and the more important considerations have historically been those associated with mechanical properties. A list of selection criteria for materials is as follows:

$>$ Static strength efficiency.

$>$ Fatigue.

$>$ Fracture toughness and crack growth.

$>$ Corrosion and unbrittlement.

$>$ Environmental stability.

Other important criteria associated with producing the basic material in the forms required and fabricating the end product at a responsible cost. These criteria are as follows:

$>$ Availability and reducibility.

$>$ Material costs.

$>$ Fabrication characteristics.

All of the criteria listed above are important to the selection of structural materials. In addition to these, the following are a few considerations that are more frequently related to specialized requirements. 
$>$ Erosion and abrasion.

$>$ Wear characteristics.

> Compatibility with other materials.

$>$ Thermal and electrical characteristics.

> Hard coatings to improve wear resistance.

$>$ Metallic plating to provide galvanic compatibility.

\section{Materials used for Brackets}

Two materials play major roles in modern aerospace: Aluminum alloys for airframes and skin, and composites for structures.

\section{Alloys}

An alloy is composed of two or more metals. The metal present in the alloy in the largest amount is called the base metal. All other metals added to the base metal are called alloying elements. Adding the alloying elements may result in a change in the properties of the base metal. For example, pure Aluminum is relatively soft and weak. However, adding small amounts or copper, manganese, and magnesium will increase Aluminum's strength many times. Heat treatment can increase or decrease an alloy's strength and hardness. Alloys are important to the aircraft industry. They provide materials with properties that pure metals do not possess.

\section{Aluminum Alloys}

Aluminum alloys are widely used in modern aircraft construction. Aluminum alloys are valuable because they have a high strength-to-weight ratio. Aluminum alloys are corrosion resistant and comparatively easy to fabricate. The outstanding characteristic of Aluminum is its lightweight. Though lightweight, commercially pure Aluminum has a tensile strength of about 13,000 psi. Cold working the metal approximately doubles its strength. Aluminum is usually alloyed with elements such as manganese, silicon, copper, magnesium, or zinc to further increase strength.

\section{Titanium Alloys}

Titanium is a lightweight, strong, corrosion- resistant metal. Recent developments make Titanium ideal for applications where Aluminum alloys are too weak and stainless steel is too heavy. Additionally, Titanium is unaffected by long exposure to seawater and marine atmosphere. Titanium is used in engine applications such as rotors, compressor blades, hydraulic system components and nacelles. Titanium $6 \mathrm{AL}-4 \mathrm{~V}$ alloy accounts for almost $50 \%$ of all alloys used in aircraft applications.

\section{Steel Alloys}

Steels are widely used as structural materials for fatigue application as they offer high fatigue strength and good process-ability at relatively low cost. Alloy steels used in aircraft construction have great strength, more so than other fields of engineering would require. These materials must withstand the forces that occur on today's modern aircraft. These steels contain small percentages of carbon, nickel, chromium, vanadium, and molybdenum.

\section{Types of aircraft loads}

The loads typically include Vertical loads Such as the weight of the engine itself,

$>$ Axial loads due to the thrust generated by the engine,

$>$ Lateral loads Such as those due to wind buffeting, and

$>$ Roll loads or moments due to rotary operation of the engine. 


\section{DESIGN OPTIMIZED 3D MODEL OF ENGINE BRACKET}

\section{Computer Aided Design}

Computer aided design helps to assist in the creation, modification, analysis, or optimization of a design using cad software. CAD software is used to increase the productivity of the designer, improve the quality of design, improve communications through documentation, and to create a database for manufacturing.

\section{About CATIA}

CATIA means Computer Aided Three Dimensional Interactive Application. CATIA is a $3 \mathrm{D}$ product Lifecycle Management software suite developed by the French Company Dassult Systems. CATIA facilitates collaborative engineering across disciplines with its 3D experience platform. CATIA allows the user to create parts in highly productive and intuitive environment. CATIA enriches existing product design with basic part and surface design tools, easily establish assembly constraints, automatically positions parts and check assembly consistency.
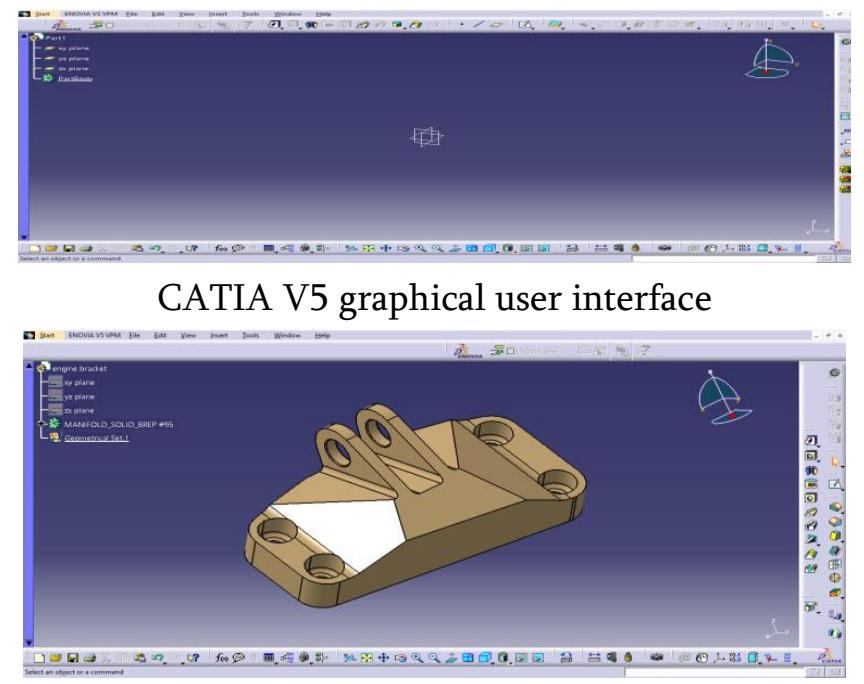

Original 3D model of engine bracket

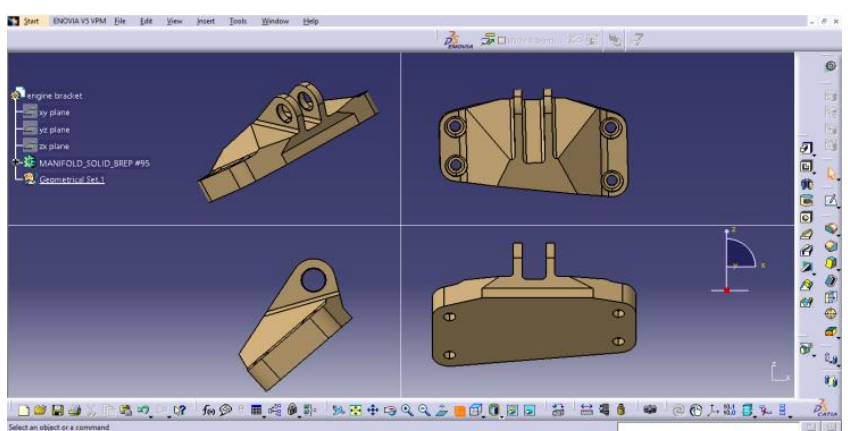

ISO view of original 3D model of engine bracket

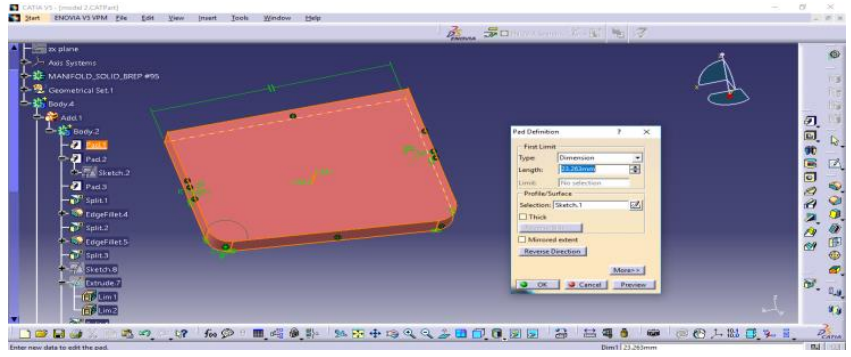

Procedure for design optimization of engine bracket

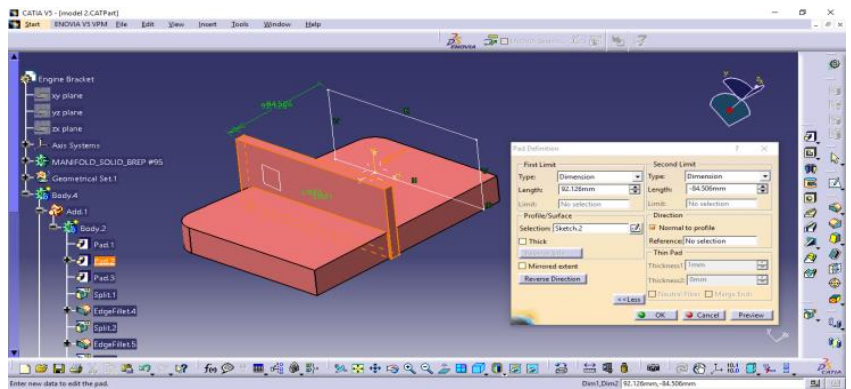

Procedure for design optimization of engine bracket

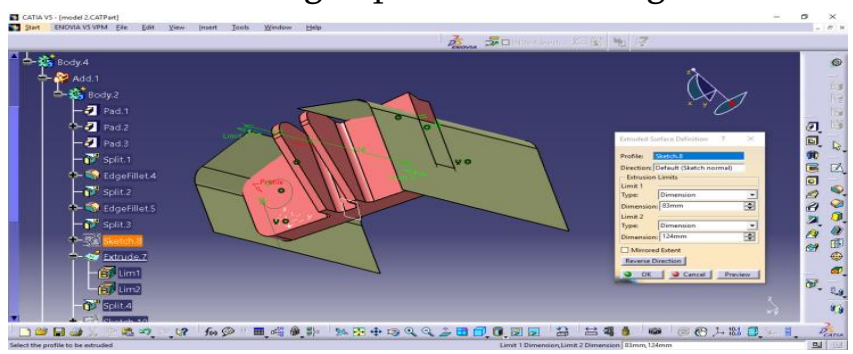

Procedure for design optimization of engine bracket

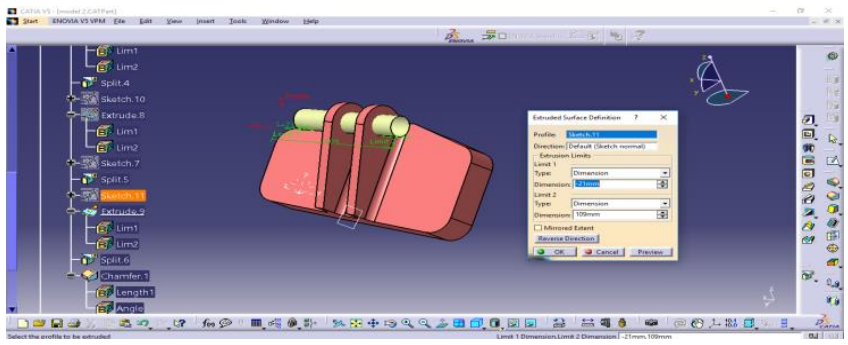

Procedure for design optimization of engine bracket 


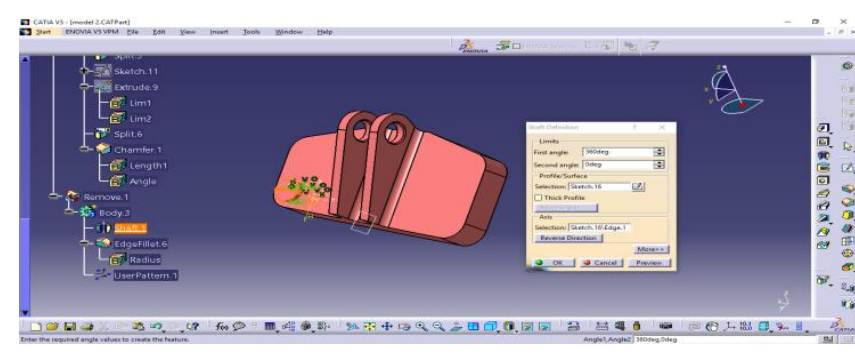

Procedure for design optimization of engine bracket

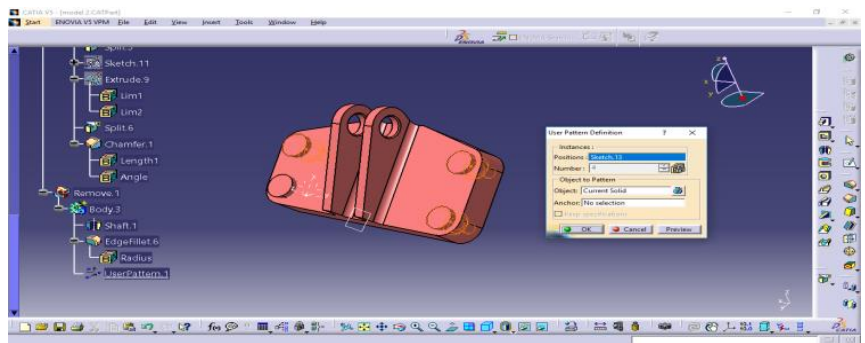

Procedure for design optimization of engine bracket

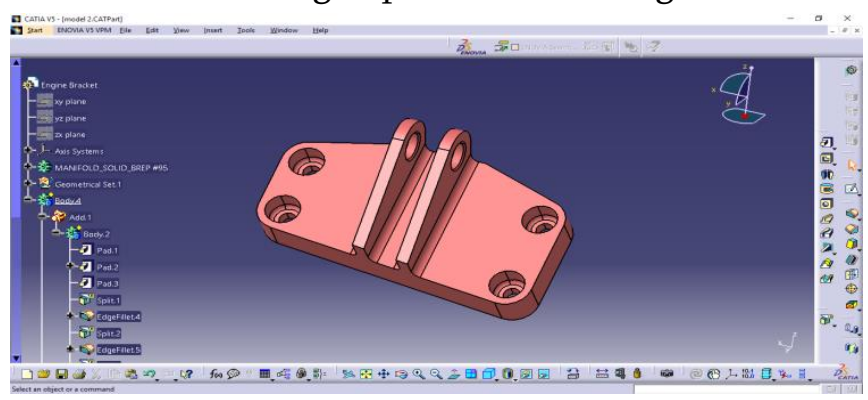

Design optimization 3D model of engine bracket

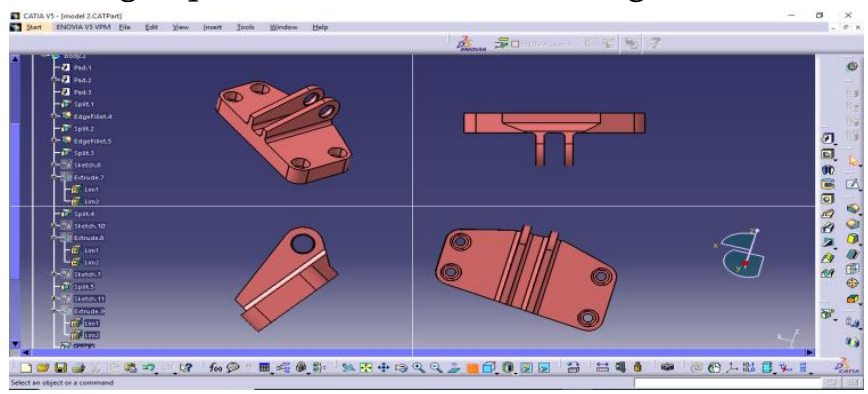

ISO view of Design optimization 3D model of engine bracket

Fig 10. Models

We changed the nonparametric model in to parametric model. The above figures shows the step by step procedure of Design optimization 3D model of engine bracket. Here we are importing this model in to MSC Patran for Linear Static Analysis.

\section{INTRODUCTION TO FEA}

Engineering analysis can be broadly divided into two categories: classical methods and numerical methods. Following tree diagram shows various methods for solving engineering problems. As shown below, the finite element method is one of several methods for solving engineering problems.

\section{Classical Methods}

$>$ Closed-form solutions are available for simple problems such as bending of beams and torsion of prismatic bars

$>$ Approximate methods using series solutions to governing differential equations are used to analyse more complex structures such as plates and shells

$>$ The classical methods can only be used for structural problems with relatively simple geometry, loading, and boundary conditions.

\section{Numerical methods}

Numerical methods address a broad range of problems. Boundary Element Method: Solves the governing differential equation for the problem with integral equations over the boundary of the domain. Only the boundary surface is meshed with elements.

Finite Difference Method: Replaces governing differential equations and boundary conditions with corresponding algebraic finite difference equations.

\section{Finite Element Method (FEM)}

> Capable of solving large, complex problems with general geometry, loading, and boundary conditions

$>$ Increasingly becoming the primary analysis tool for designers and analysts

$>$ The Finite Element Method is also known as the Matrix Method of Structural Analysis in the 
literature because it uses matrix algebra to solve the system of simultaneous equations.

\section{Finite Element Analysis}

Finite element method is a method of investigating the behaviour of complex structures by breaking them down into smaller, simpler pieces. These smaller pieces of structure are called (finite) elements. The elements are connected to each other at nodes. The finite element method offers virtually unlimited problem generality by permitting the use of elements of various regular shapes. These elements can be combined to approximate any irregular boundary. In similar fashion, loads and constraints of any type can be applied. Problem generality comes at the expense of insight a finite element solution is essentially a stack of numbers that applies only to the particular problem posed by the finite element model. Changing any significant aspect of the model generally requires a complete reanalysis of the problem.

\section{Types of Finite Elements}

Finite elements have shapes which are relatively easy to formulate and analyse. The three basic types of finite elements are beams, plates, and solids.

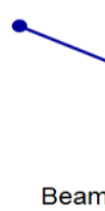

(1D)

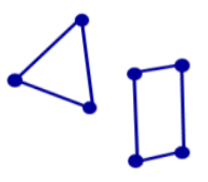

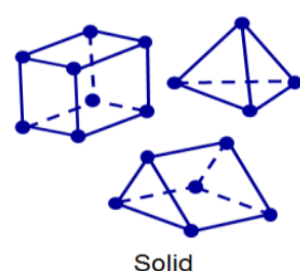

(3D)
Fig 11. Finite element geometries

Elements are known geometry entities having global equations for calculating its characteristics under working conditions. Based on structural geometry and behaviour we can categorise it into 3 types as shown in the figures.

\section{One Dimensional Elements}

A one-dimensional element is one in which the properties of the element are defined along a line or curve. Typical applications for the one-dimensional element include truss structures, beams, stiffeners, and many others.1D beam elements are used to model long, slender structural members as demonstrated in this communications tower finite element model.
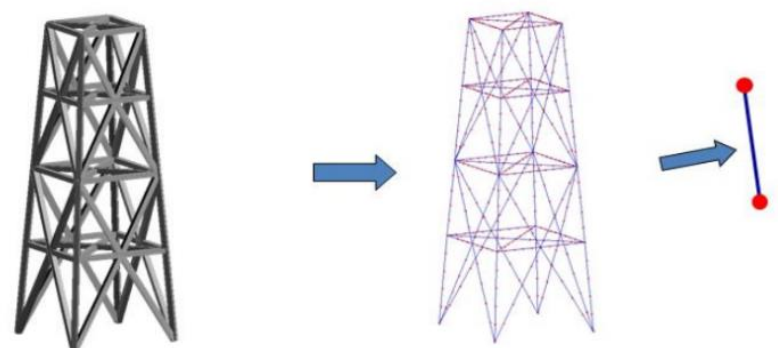

Fig 12. 1D elements example-Tower

\section{Two Dimensional Elements}

Two-dimensional elements, commonly referred to as plate and shell elements, are used to represent areas in your model where one of the dimensions is small in comparison to the other two. 2D plate elements are used to model thin structural members such as aircraft fuselage skin or car body. In the finite element field, the membrane stiffness of the twodimensional elements can be calculated using one of two theories: "plane stress" or "plane strain." In the plane strain theory, the assumption is made that the strain across the thickness $t$ is constant. Note that a two-dimensional element can be in either plane stress or plane strain, but not both.

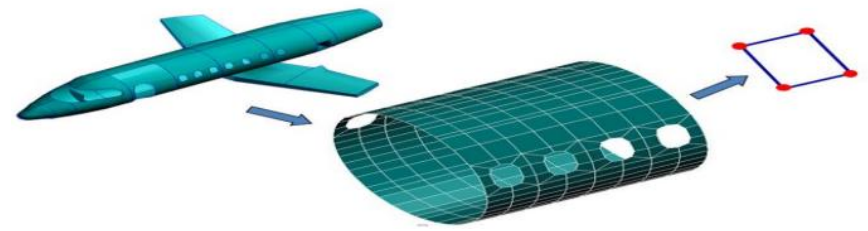

Fig 13. 2D Elements example-plane structure 


\section{Three-Dimensional Elements}

Whenever you need to model a structure that does not behave as a bar or plate structure under the applied loads, you need to use one or more of the three-dimensional elements. The three-dimensional elements are commonly referred to as solid elements. Typical engineering applications of solid elements include engine blocks, brackets, and gears.
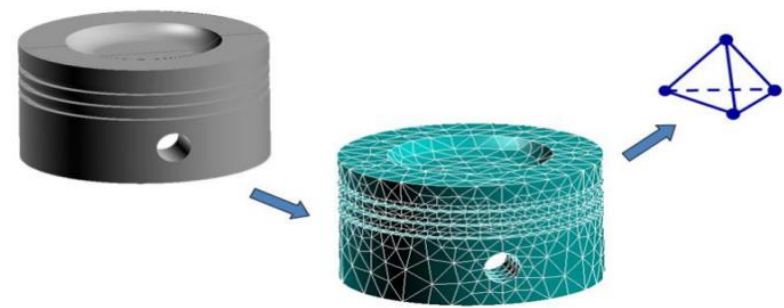

Fig 14. 3D Elements example-piston

As a final comment on all of the elements, the purpose of this chapter is to discuss the commonly used elements and their applications to typical engineering problems. The elements are discussed in order of their size in terms of the number of degreesof-freedom they are not discussed in order of importance.

\section{About MSC PATRAN, NASTRAN}

NASTRAN is a finite element analysis (FEA) program that was originally developed for NASA in the late 1960s under United States government funding for the Aerospace industry. The MacNeal-Schwendler Corporation (MSC) was one of the principal and original developers of the public domain NASTRAN code MSC. Software is pleased to introduce you to the exciting new technologies in MSC Nastran, the premier and trusted CAE solution for aerospace, automotive, medical, defence, and manufacturing industries worldwide. This release includes new features and enhancements in Contact, High Performance Computing, Acoustics, Aeroelasticity, and Explicit Nonlinear SOL 700.
MSC nastran does not have any graphical user interface like other software. It completely communicates by using scripting language or any other pre and post software like Patran, Simxpert and Hypermesh. It has the following capabilities include

$>$ Linear static analysis

$>$ Static analysis with geometric and material nonlinearity

$>$ Transient analysis with geometric and material nonlinearity

$>$ Normal modes analysis

$>$ Buckling analysis

$>$ Direct and modal complex eigenvalue analysis

$>$ Direct and modal frequency analysis (including random analysis)

> Direct and modal transient analysis (including response spectrum analysis)

> Linear cyclic symmetry (including static, normal modes, buckling, and direct frequency response)

$>$ Linear and nonlinear steady state heat transfer

$>$ Linear and nonlinear transient heat transfer

$>$ Aero elasticity

> Substructure analysis (super elements)

$>$ Design sensitivity and optimization

$>$ Acoustics

$>$ Composite Material Analysis

$>$ p-elements

The following figurer shows pre-processing, solver and post processor steps and functions of solver and pre \& post processor.

Meshing a model consists of several tasks:

$>$ Create appropriate geometry

$>$ Parametric or non-parametric

$>$ Remove unneeded features, e.g. small corners

$>$ Specify the element topology (e.g. parabolic) and size

$>$ Specify a mesher, e.g. Paver, for each region 
> Specify how the meshers will be controlled

$>$ Nastran has several meshing algorithms:

- IsoMesh (mapped mesher)

- Paver (free mesher)

- TetMesh

- Sweep mesh

The iso-mesher (IsoMesh) is used to mesh

- All curves (parametric) (yellow)

- Simple (parametric) surfaces (green)

- Simple (parametric) solids (blue)

Geometry must be parametric

- Nodes are placed at the intersection of curves of constant parametric value, and of surfaces

- If geometry is not parametric, IsoMesh cannot place nodes

Figurer shows deferent mesh patterns,
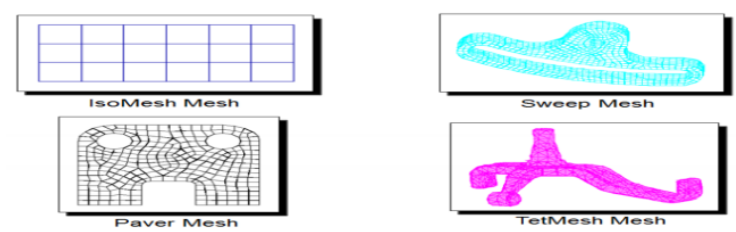

Fig 15. Mesh patterns

\section{Loads \& Boundary conditions}

A constraint is the enforcement of a prescribed displacement (i.e., component of translation or rotation) on a grid point or points. There are two basic types of constraints in MSC Nastran:

- Single point constraints (SPCs)

- Multipoint constraints (MPCs).

A single point constraint is a constraint applied to an individual grid point. Single point constraints can enforce either zero displacement or nonzero displacement.

A multipoint constraint is a mathematical constraint relationship between one grid point and another grid point (or set of grid points). User defined multipoint constraints are beyond the scope of this book we will concentrate on single point constraints. The boundary conditions of a static structure (fixed, hinged, roller support, etc.) typically require that various degrees of freedom be constrained to zero displacement. For example, consider a grid point fixed in a rigid wall. All six displacement degrees of freedom three translational directions and three rotational directions must be constrained to zero in order to mathematically describe the fixed boundary condition. Rigid Body Motion and Mechanisms describes how boundary conditions are used to prevent rigid body motion-the presence of rigid body motion in an MSC Nastran static analysis will cause the run to fail.

\section{Linear Static Analysis}

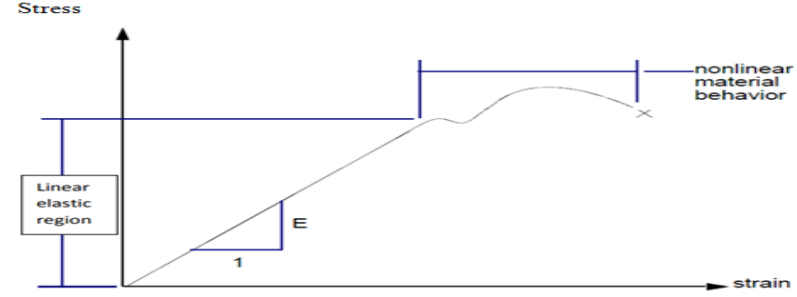

Fig 16. Stress-Strain relationship for linear static analysis

Linear means straight line. $\sigma=\mathbf{e}$ Eis equation of straight line $(\mathrm{y}=\mathrm{mx})$ passing through origin. "E" Elastic modulus is slope of the curve \& is a constant. In real life after crossing yield point material follows non-linear curve but software follows same straight line. Component break into two separate pieces after crossing ultimate stress but software based analysis never show failure in this fashion.

Linear static problems are solved in one step-a single decomposition of the stiffness matrix. Nonlinear problems of any type require iterative solution methods and incremental loading to obtain (converge to) a solution, and are generally far more computationally intensive than linear problems. 


\section{ANALYSIS OF BRACKET}

\section{Material and Element Properties}

We assume that the material is a continuum (contains no gaps or voids) and that all material properties remain constant.

In this project we are doing analysis using three different materials. These material properties are taken from MSC Software material library,

1. 2024-T3 Aluminum alloy,

2. Titanium $6 \mathrm{AL}-4 \mathrm{~V}$ and,

3. 15-5PH (H1025) Stainless steel.

\section{Chemical Composition of Materials}

1. Chemical Composition of 2024-T3 Aluminum alloy

\begin{tabular}{|c|c|}
\hline Component & Weight \% \\
\hline $\mathrm{Al}$ & 93.50 \\
\hline $\mathrm{Cu}$ & 4.4 \\
\hline $\mathrm{Mg}$ & 1.5 \\
\hline $\mathrm{Mn}$ & 0.6 \\
\hline $\mathrm{Cr}$ & $\operatorname{Max} 0.1$ \\
\hline $\mathrm{Si}$ & $\operatorname{Max} 0.5$ \\
\hline $\mathrm{Ti}$ & Max 0.15 \\
\hline
\end{tabular}

Table 1. Chemical Composition of 2024-T3 Aluminum alloy

2. Chemical Composition of Titanium 6AL-4V alloy

\begin{tabular}{|c|c|}
\hline Component & Weight $\%$ \\
\hline $\mathrm{Al}$ & 6 \\
\hline $\mathrm{Fe}$ & Max 0.25 \\
\hline $\mathrm{O}$ & $\operatorname{Max} 0.2$ \\
\hline $\mathrm{Ti}$ & 90 \\
\hline $\mathrm{V}$ & 4 \\
\hline
\end{tabular}

Table 2: Chemical Composition of Titanium 6AL-4V alloy
3. Chemical Composition of 15-5PH (H1025) Stainless steel

\begin{tabular}{|c|c|}
\hline Component & Weight \% \\
\hline $\mathrm{Fe}$ & 75 \\
\hline $\mathrm{Cr}$ & 14.48 \\
\hline $\mathrm{Cu}$ & 3.5 \\
\hline $\mathrm{C}$ & 0.07 \\
\hline $\mathrm{Ni}$ & 4.5 \\
\hline $\mathrm{Mn}$ & Max 1 \\
\hline $\mathrm{Si}$ & Max 1 \\
\hline
\end{tabular}

Table 3. Chemical Composition of 15-5PH (H1025) Stainless steel

Material properties of different metals

\begin{tabular}{|l|c|r|l|}
\hline \multicolumn{4}{|c|}{ Titanium 6AL-4V alloy } \\
\hline Youngs Modulus & $\mathrm{E}$ & $1.10 \mathrm{E}+05$ & $\mathrm{Mpa}$ \\
\hline Shear Modulus & $\mathrm{G}$ & $4.40 \mathrm{E}+04$ & $\mathrm{Mpa}$ \\
\hline Poissons Ratio & $\mathrm{Mu}$ & 0.342 & \\
\hline Density & $\mathrm{Rho}$ & 4430 & $\mathrm{Kg} / \mathrm{m}^{3}$ \\
\hline
\end{tabular}

Table 4. Material properties of Titanium

\begin{tabular}{|l|c|r|l|}
\hline \multicolumn{4}{|c|}{ 2024-T3 Aluminum alloy } \\
\hline Youngs Modulus & $\mathrm{E}$ & $7.00 \mathrm{E}+04$ & $\mathrm{Mpa}$ \\
\hline Shear Modulus & $\mathrm{G}$ & $4.40 \mathrm{E}+04$ & $\mathrm{Mpa}$ \\
\hline Poissons Ratio & $\mathrm{Mu}$ & 0.3 & \\
\hline Density & $\mathrm{Rho}$ & 2780 & $\mathrm{Kg} / \mathrm{m}^{3}$ \\
\hline
\end{tabular}

Table 5. Material properties of Aluminum

\begin{tabular}{|l|c|r|l|}
\hline \multicolumn{4}{|c|}{ 15-5PH (H1025) Stainless steel } \\
\hline Youngs Modulus & $\mathrm{E}$ & $2.10 \mathrm{E}+05$ & $\mathrm{Mpa}$ \\
\hline Shear Modulus & $\mathrm{G}$ & $4.40 \mathrm{E}+04$ & $\mathrm{Mpa}$ \\
\hline Poissons Ratio & $\mathrm{Mu}$ & 0.3 & \\
\hline Density & $\mathrm{Rho}$ & 7.8 & $\mathrm{Kg} / \mathrm{m}^{3}$ \\
\hline
\end{tabular}

Table 6. Material properties of Steel

Meshing For Engine Bracket

A. Original Geometrical model

Model Summary: 
Number of nodes $=59502$

Number of elements $=280218$

Number of Rigid Element $=5$

Number of RBE2 element $=4$

Number of RBE3element $=1$

TETRA4: 280213

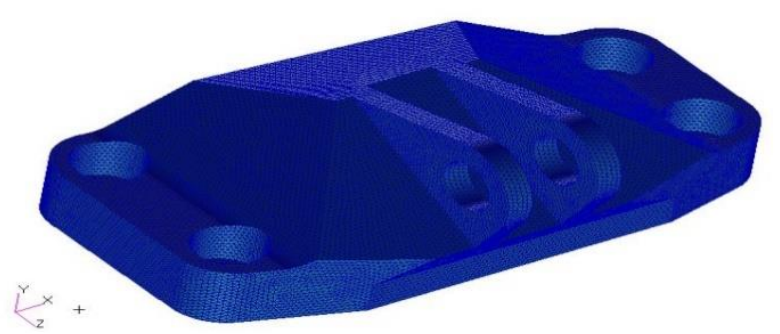

Fig 17. Original meshed model of engine bracket

\section{B. Optimized Meshed Finite Element Model}

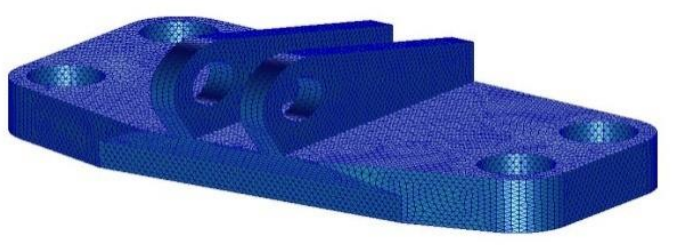

Fig 18. Optimized meshed model of bracket

\section{Model Summary:}

Number of nodes $=32385$

Number of elements $=147000$

Number of Rigid Element $=5$

Number of RBE2 element $=4$

Number of RBE3element $=1$

TETRA4: 146995

\section{Loads and boundary conditions}

Load conditions taken from below reference 1.For this Linear Static Analysis the following boundary conditions are applied.

\begin{tabular}{|l|c|c|}
\hline \multicolumn{1}{|c|}{ Load Case } & Applied Load & Units \\
\hline Vertical & 35586 & $\mathrm{~N}$ \\
\hline Horizontal & 37810 & $\mathrm{~N}$ \\
\hline
\end{tabular}

\begin{tabular}{|l|c|c|}
\hline $\begin{array}{l}\text { Angle of } 42^{0} \text { from } \\
\text { vertical }\end{array}$ & 42258 & $\mathrm{~N}$ \\
\hline
\end{tabular}

Table 7: Load conditions for analysis

Here RBE2 elements for four bolts and those are constrained. RBE3 element for apply load.

The below figure shows the positions of Loads and boundary conditions. The force value of $35586 \mathrm{~N}$ applied at center in downward direction is shown in figure.

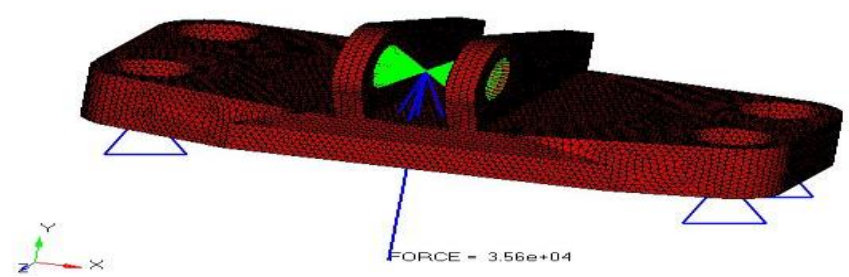

Fig 19. Loads and boundary conditions of Vertical load case

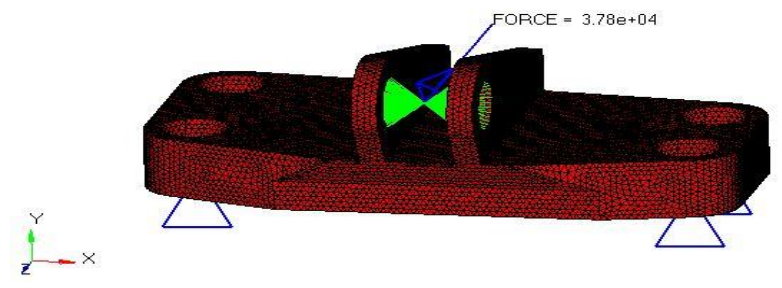

Fig 20. Loads and boundary conditions of Horizontal load case

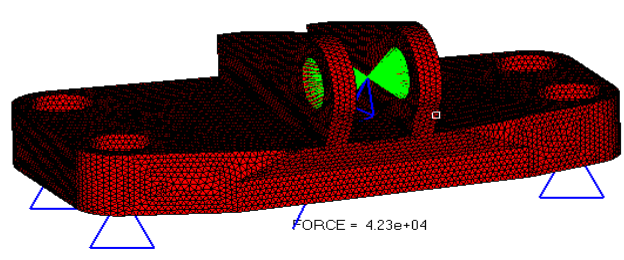

Fig 21. Loads and boundary conditions of Angle of $42^{\circ}$ from vertical load case

\section{Linear Static Analysis of Bracket}

Note: In this project we solved for three load conditions with three different materials such as 
2024-T3 Aluminum alloy, Titanium 6AL-4V and 155PH (H1025) Stainless steel. Below discussed results for 2024-T3 Aluminum alloy for three load cases of Vertical, Horizontal, and Angle of $42^{\circ}$ from vertical.

\section{(A) Original Geometrical model}

Material type: 2024-T3 Aluminum

Load case1: Vertical
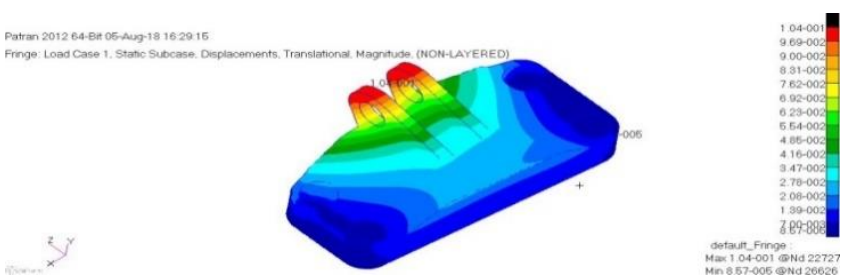

Fig 22. Displacements for vertical load
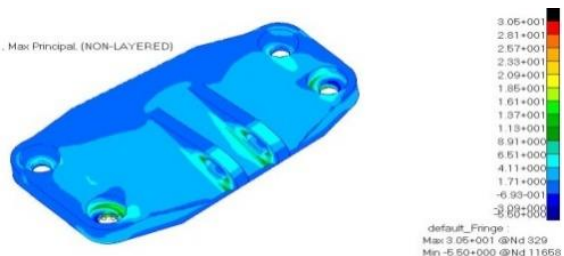

Fig 23. Max Principal Stress for vertical load
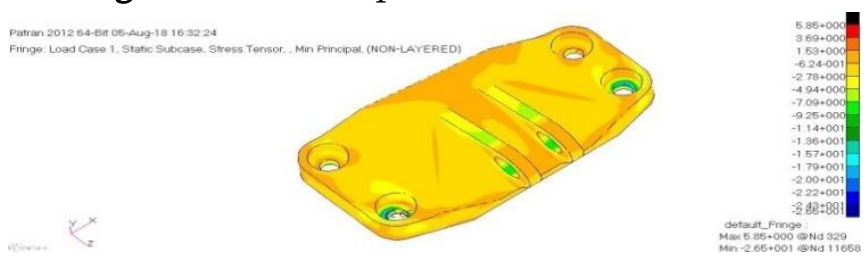

Fig 24. Min Principal Stress for vertical load

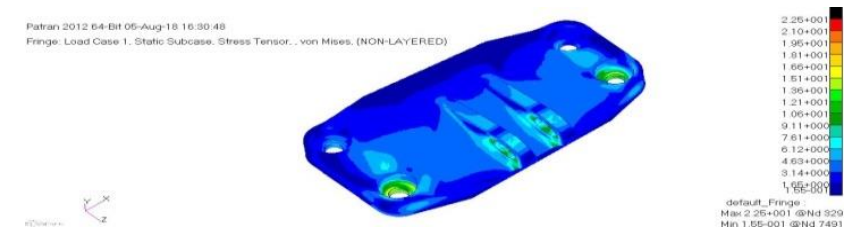

Fig 25. Equivalent (Von-Mises) stress for vertical load

Load case 2: Horizontal
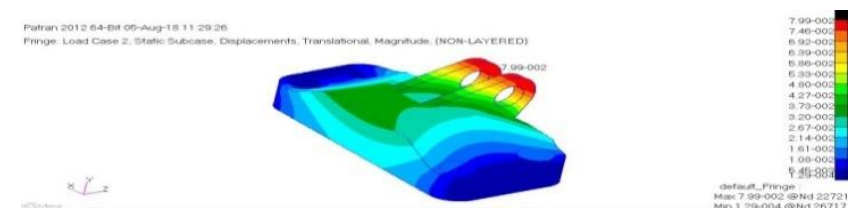

Fig 26. Displacements for Horizontal load

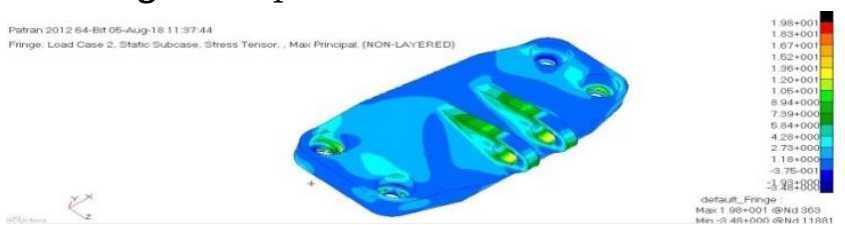

Fig 27. Max Principal Stress for Horizontal load

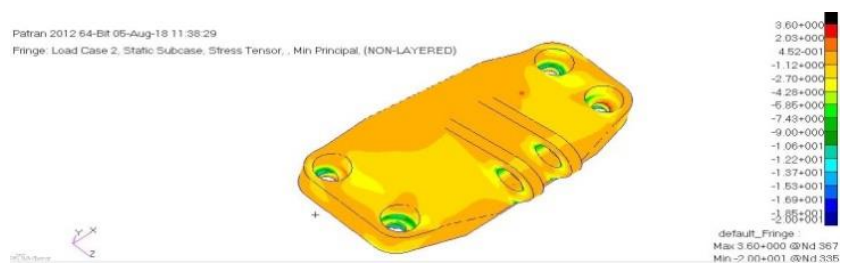

Fig 28. Min Principal Stress for Horizontal load

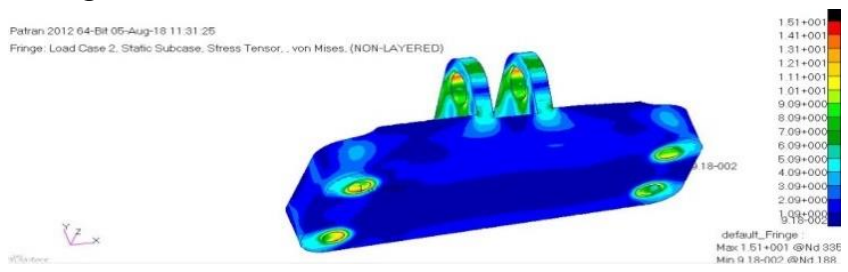

Fig 29. Equivalent (Von-Mises) Stress for Horizontal load

Load case 3: Angle of $42^{\circ}$ from vertical
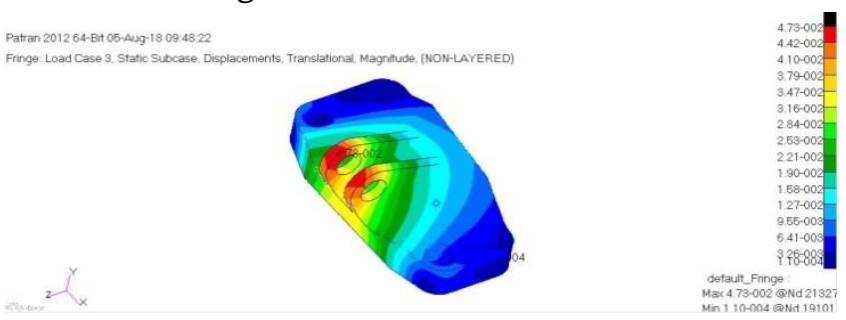

Fig 30. Displacement for Angle of $42^{0}$ from vertical

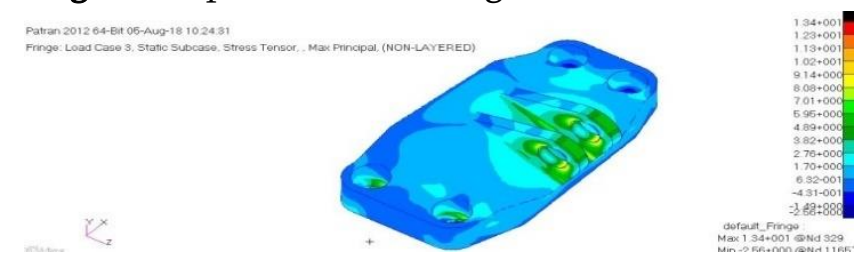

Fig 31.Max-principal Stress for Angle of $42^{\circ}$ from

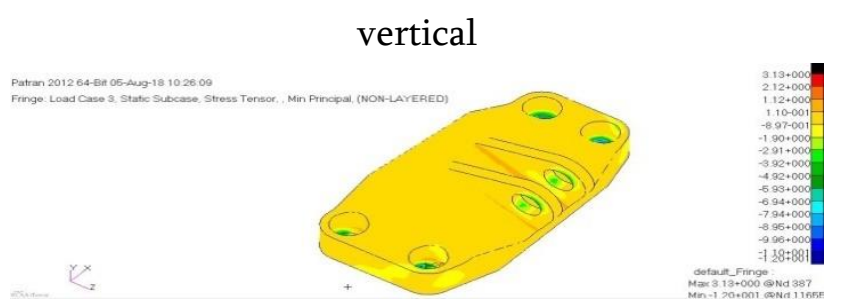

Fig 32. Min-principal Stress for Angle of $42^{\circ}$ from vertical
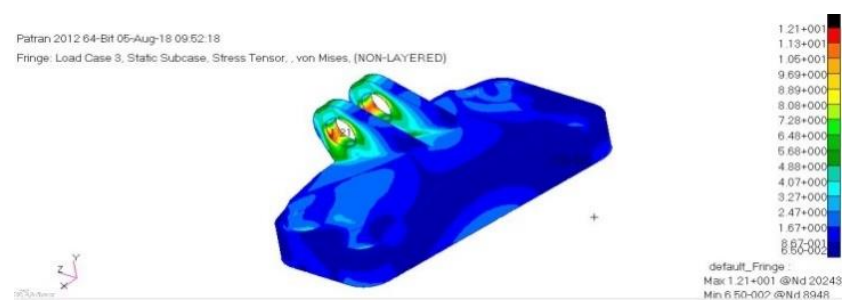

Fig 33. Equivalent (Von-Mises) stress for Angle of $42^{0}$ from vertical

(B) Optimized model 
Load case1: Vertical
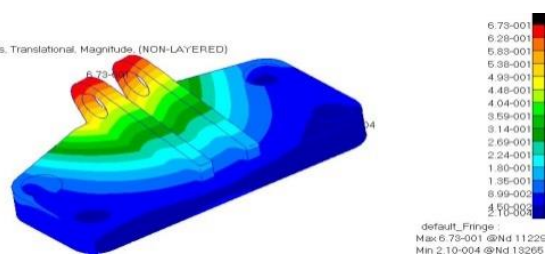

Fig 34. Displacements for vertical load

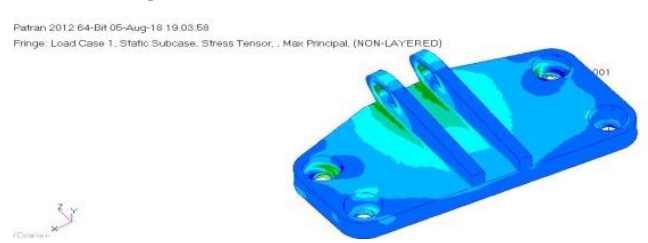

Fig 35. Max-principal Stress for vertical load
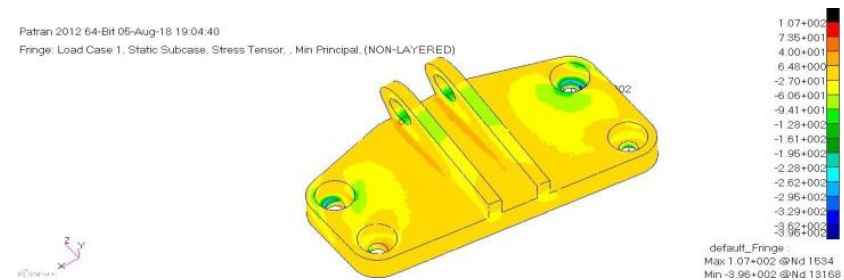

Fig 36. Min-principal Stress for vertical load
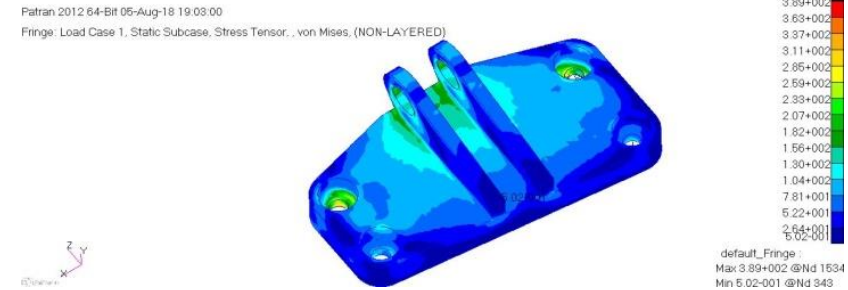

Fig 37. Equivalent (Von-Mises) stress for vertical load

Load case 2: horizontal
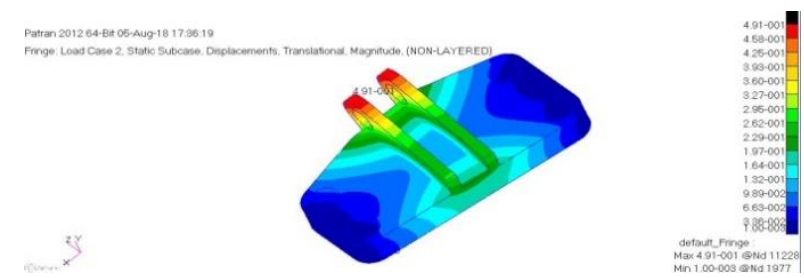

Fig 38. Displacements for horizontal load
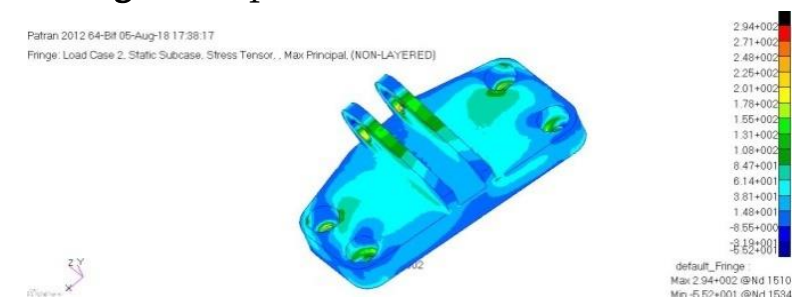

Fig 39. Max-principal stress for horizontal load

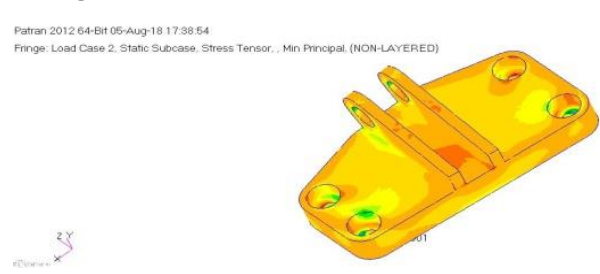

Fig 40. Min Principal Stress for horizontal load

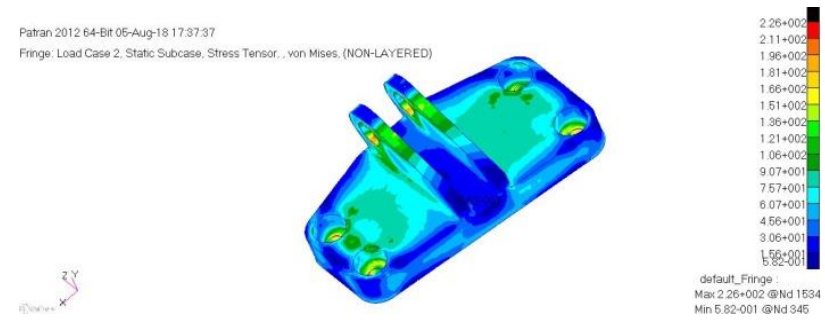

Fig 41.Equivalent (Von-Mises) stress for horizontal load

Load case 3: Angle of $42^{\circ}$ from vertical

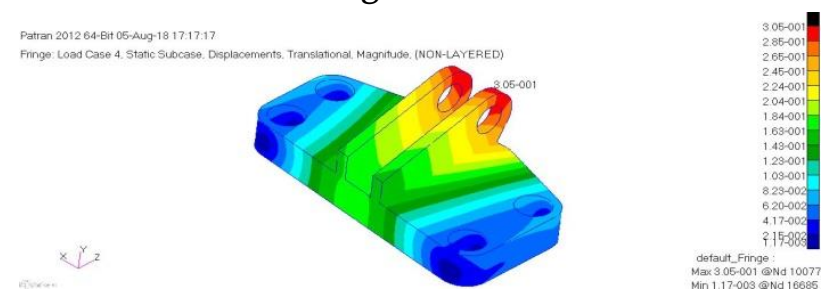

Fig 42.Displacement for Angle of $42^{\circ}$ from vertical

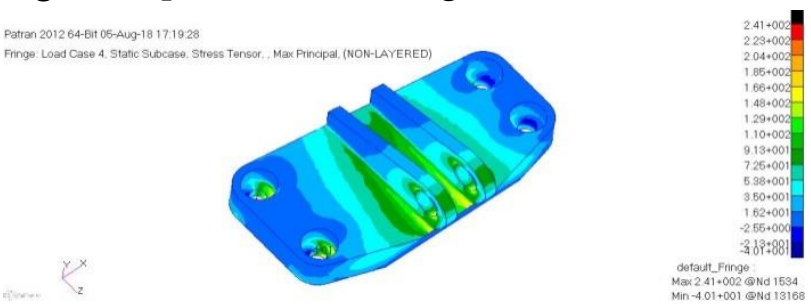

Fig 43. Max-principal Stress for Angle of $42^{\circ}$ from vertical

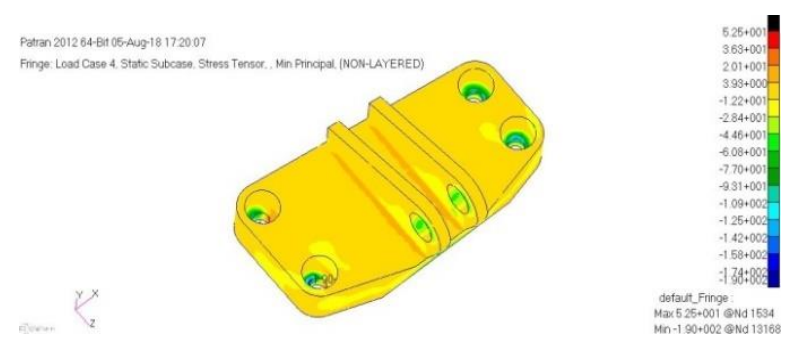

Fig 44. Min-principal Stress for Angle of $42^{\circ}$ from vertical
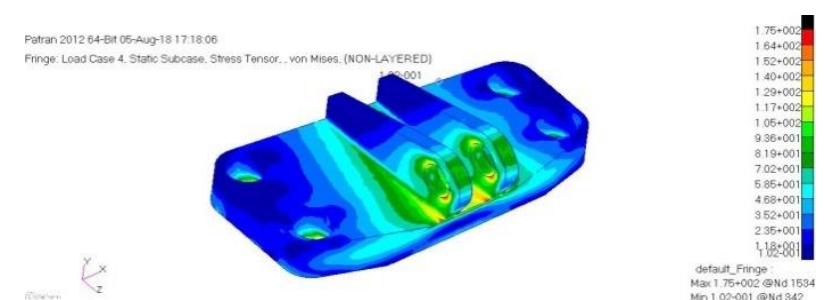

Fig 45. Equivalent (Von-Mises) stress for Angle of $42^{\circ}$ from vertical

VI. INTRODUCTION OF FATIGUE

Fracture Mechanics 
Fracture mechanics is the field of mechanics concerned with the study of the propagation of cracks in materials. It uses methods of analytical solid mechanics to calculate the driving force on a crack and those of experimental solid mechanics to characterize the material's resistance to fracture.

In modern materials science, fracture mechanics is an important tool in improving the mechanical performance of mechanical components. It applies the physics of stress and strain, in particular the theories of elasticity and plasticity, to the microscopic crystallographic defects found in real materials in order to predict the macroscopic mechanical failure of bodies. Fractography is widely used with fracture mechanics to understand the causes of failures and also verify the theoretical failure predictions with real life failures. The prediction of crack growth is at the heart of the damage tolerance discipline.

There are three ways of applying a force to enable a crack to propagate:

Mode I fracture - Opening mode (a tensile stress normal to the plane of the crack),

Mode II fracture - Sliding mode (a shear stress acting parallel to the plane of the crack and perpendicular to the crack front), and

Mode III fracture - Tearing mode (a shear stress acting parallel to the plane of the crack and parallel to the crack front).

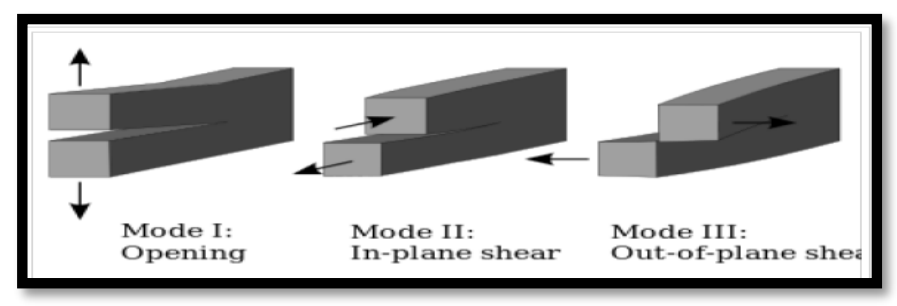

Fig 46. Modes of failure
Fatigue is the failure caused by application of repetitive load by the process of initiation of cracks and growth.

Fatigue cracks are most frequently initiated at sections in a structural member where changes in geometry, e.g. holes, notches or sudden changes in section, cause stress concentrations. Designers seek to eliminate such areas by ensuring that rapid changes in section are as smooth as possible. At re-entrant corners for example, fillets are provided as shown in Fig
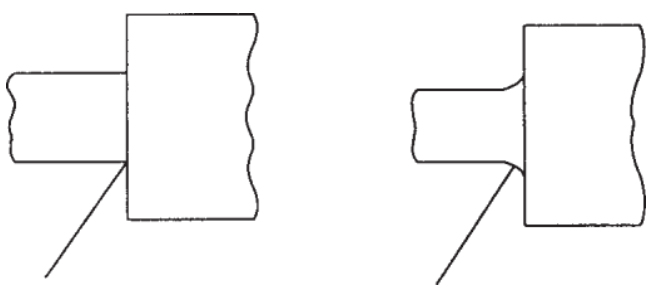

Fig 47. Location of stress concentration

Provision of fillet minimizes stress concentration Stress concentration locations

The value of $S_{\text {alt }}$ is the most important factor in determining the number of cycles of load that produce failure. The stress $S_{\text {alt }}$ that can be withstood for a specified number of cycles is called the fatigue strength of the material. Some materials, such as mild steel, possess a stress level that can be withstood for an indefinite number of cycles. This stress is known as the endurance limit of the material; no such limit has been found for Aluminum and its alloys. Fatigue data are frequently presented in the form of an $\mathrm{S}-\mathrm{n}$ curve or stress-endurance curve as shown in Fig.

\section{Fatigue}




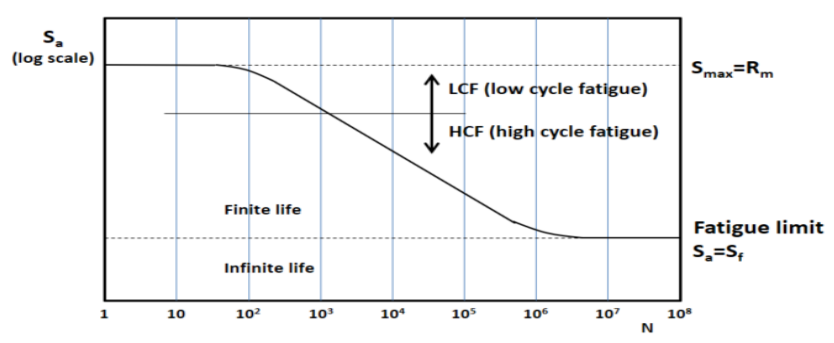

Fig 48. S-N Curve

Fatigue properties of materials are often described using the fatigue limit or the S-N curve (fatigue curve, Wohler curve). The S-N curve describes the relation between cyclic stress amplitude and number of cycles to failure. The figure below shows a typical S-N curve. On the horizontal axis the number of cycles to failure is given on logarithmic scale. On the vertical axis (either linear or logarithmic) the stress amplitude (sometimes the maximum stress) of the cycle is given. $\mathrm{S}-\mathrm{N}$ curves are derived from fatigue tests. Tests are performed by applying a cyclic stress with constant amplitude (CA) on specimens until failure of the specimen. In some cases the test is stopped after a very large number of cycles $\left(\mathrm{N}>10^{6}\right)$. The results are then interpreted as infinite life.

High Cycle Fatigue (HCF): component subjected to less sever loads and life $>10^{5}$ cycles. In this region the material behaviour is fully elastic. On log-log scale the $\mathrm{S}-\mathrm{N}$ curve can be considered to be linear.

Low Cycle Fatigue (LCF): life of component is less than 100000cycles, applicable for heavy duty application loading. If the maximum stress level in a cycle is exceeding the yield strength, the material behaviour in the net section will be predominantly plastic. Number of cycles to failure will be very small. Usually a strain-life curve instead of the $\mathrm{S}-\mathrm{N}$ curve is used to describe the fatigue behaviour.

That the actual distinction between HCF and LCF is not defined by a certain number of cycles but by the amount of plasticity in the net section, i.e. the stress level.

Infinite Life: Stress level below whichmaterial never fails known as endurance limit or fatigue limit. Never fails or infinite life is a relative term. For steel, test is stooped after $2^{*} 10^{6}$ cycles (in case if till then failure is not detected) and said to have infinite life. This is the point where the S-N curve slop changes and it becomes parallel to $\mathrm{x}$-axis.

Unlike steel, non-ferrous alloys have no specific endurance limit (S-N curve never become parallel to $\mathrm{x}$-axis. The level of the fatigue limit depends on many factors, such as geometry (stress concentration factor $\mathrm{Kt}$ ), mean stress (stress ratio), surface conditions, corrosion, temperature, and residual stresses.

\section{Different Phases of fatigue Life}

The crack starts as a slip band within a grain. The cyclic slip occurs as a result of cyclic shear stress, this slip leads to formation of slip steps, in the present of oxygen, the freshly exposed surface of the material in slip steps get oxidized, which prevents slip reversal. The slip reversal in this case occurs in some adjacent slip plane, thereby leading to formation of extrusions and intrusions on the surface of the material as shown in the figure below.

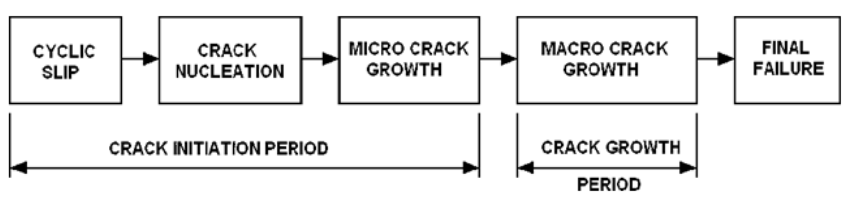

Fig 49. Different phases of the fatigue life

The fatigue life $\left(\mathrm{N}_{\mathrm{f}}\right)$ of a component is defined by the total number of stress cycles required to cause failure. Fatigue life can be separated into three stages where:

$$
\mathrm{N}_{\mathrm{f}}=\mathrm{N}_{\mathrm{i}}+\mathrm{N}_{\mathrm{p}}
$$

\section{Crack initiation $\left(\mathrm{N}_{\mathrm{i}}\right)$}


This is the number of cycles required to initiate a crack. It generally results from dislocation pile-ups and imperfections such as surface roughness, voids, scratch etc. hence; in this period fatigue is a material surface phenomenon.

The stress concentration factor, $\mathrm{K}_{\mathrm{t}}$ is another factor to be considered in crack initiation prediction.

\section{Crack growthN $\mathrm{N}_{\mathrm{p}}$}

This is the number of cycles required to grow the crack in a stable manner to a critical size, generally controlled by stress level. Since most common material contains flaws, the prediction of crack growth is the most studied aspect of fatigue. Crack growth resistance, when the crack penetrates the material, depends on the material as a bulk property. It is no longer a surface phenomenon. The stress intensity factor is an important factor for fatigue growth prediction.

\section{Rapidfracture}

Very rapid critical crack growth occurs when the crack length reaches a critical value. Since rapid fracture occurs quickly, there is no rapid fracture term in the fatigue life expression.

The fracture toughness $\mathrm{K}_{\mathrm{IC}}$ of the material is the primary factor for rapid fracture prediction or design against fracture.

\section{VII.FATIGUE CALCULATIONS OF AIRCRAFT ENGINE BRACKET}

Note:Here we discussed the calculations for 2024-T3 Aluminum alloyof three load conditions.

\section{(A) Original Model}

Fatigue life Equation for 2024-T3 Aluminum alloy:

Load case 1: Vertical

$$
\begin{gathered}
S_{\text {eq }}=S_{\max }(1-R)^{0.56} \\
S_{\text {eq }}=30.50(1-0.1)^{0.56}
\end{gathered}
$$

$$
\begin{aligned}
& \mathrm{S}_{\text {eq }}=28.75 \mathrm{Mpa} \\
& \log N_{f}=11.1-3.97 \log \left(S_{\text {eq }}-15.8\right) \\
& \log N_{f}=10^{\wedge} 5^{*}\left(10^{\wedge}\left(11.1-3.97^{*} \log (28.75-15.8)\right)\right) \\
& \log \mathrm{N}_{\mathrm{f}}=4.83 \mathrm{E}+11 \mathrm{~N}
\end{aligned}
$$

Load case 2: Horizontal

$$
\begin{gathered}
S_{\text {eq }}=S_{\max }(1-R)^{0.56} \\
S_{\text {eq }}=15.10(1-0.1)^{0.56} \\
S_{\text {eq }}=14.23 \mathrm{Mpa}
\end{gathered}
$$$$
\log \mathrm{N}_{\mathrm{f}}=11.1-3.97 \log \left(\mathrm{S}_{\text {eq }}-15.8\right)
$$

$\log \mathrm{N}_{\mathrm{f}}=10^{\wedge} 5^{*}\left(10^{\wedge}\left(11.1-3.97^{*} \log (14.23-15.8)\right)\right)$

$\log N_{f}=2.13 E+15 N$

Load case 3: Angle of $42^{\circ}$ from vertical

$$
\begin{gathered}
S_{\text {eq }}=S_{\max }(1-R)^{0.56} \\
S_{\text {eq }}=12.10(1-0.1)^{0.56} \\
S_{\text {eq }}=11.41 \mathrm{Mpa}
\end{gathered}
$$$$
\log \mathrm{N}_{\mathrm{f}}=11.1-3.97 \log \left(\mathrm{S}_{\text {eq }}-15.8\right)
$$

$\log N_{\mathrm{f}}=10^{\wedge} 5^{*}\left(10^{\wedge}\left(11.1-3.97^{*} \log (11.41-15.8)\right)\right)$

$\log \mathrm{N}_{\mathrm{f}}=3.53 \mathrm{E}+13 \mathrm{~N}$

\section{(B) Featured Model}

Fatigue life Equation for 2024-T3 Aluminum alloy:

Load case 1: Vertical

$$
\begin{gathered}
\mathrm{S}_{\text {eq }}=\mathrm{S}_{\max }(1-\mathrm{R})^{0.56} \\
\mathrm{~S}_{\text {eq }}=530(1-0.1)^{0.56} \\
\mathrm{~S}_{\text {eq }}=499.63 \mathrm{Mpa}
\end{gathered}
$$$$
\log N_{f}=11.1-3.97 \log \left(S_{\text {eq- }}-15.8\right)
$$

$\log \mathrm{N}_{\mathrm{f}}=10^{\wedge} 5^{*}\left(10^{\wedge}\left(11.1-3.97^{*} \log (499.63-15.8)\right)\right)$

$$
\log \mathrm{N}_{\mathrm{f}=}=2.77 \mathrm{E}+05 \mathrm{~N}
$$

Load case 2: Horizontal

$$
\begin{aligned}
& \mathrm{S}_{\text {eq }}=\mathrm{S}_{\max }(1-\mathrm{R}){ }^{0.56} \\
& S_{\text {eq }}=294(1-0.1)^{0.56} \\
& \mathrm{~S}_{\text {eq }}=277.16 \mathrm{Mpa} \\
& \log N_{f}=11.1-3.97 \log \left(S_{\text {eq }}-15.8\right) \\
& \log \mathrm{N}_{\mathrm{f}}=10^{\wedge} 5^{*}\left(10^{\wedge}\left(11.1-3.97^{*} \log (277.16-15.8)\right)\right) \\
& \log \mathrm{N}_{\mathrm{f}}=3.19 \mathrm{E}+06 \mathrm{~N}
\end{aligned}
$$

Load case 3: Angle of $42^{\circ}$ from vertical

$$
\begin{gathered}
\mathrm{S}_{\text {eq }}=\mathrm{S}_{\max }(1-\mathrm{R})^{0.56} \\
\mathrm{~S}_{\text {eq }}=241(1-0.1)^{0.56} \\
\mathrm{~S}_{\text {eq }}=227.19 \mathrm{Mpa} \\
\log \mathrm{N}_{\mathrm{f}=} 11.1-3.97 \log \left(\mathrm{S}_{\text {eq }}-15.8\right)
\end{gathered}
$$


$\log \mathrm{N}_{\mathrm{f}}=10^{\wedge} 5^{*}\left(10^{\wedge}\left(11.1-3.97^{*} \log (227.19-15.8)\right)\right)$

$$
\log \mathrm{N}_{\mathrm{f}=} 7.40 \mathrm{E}+06 \mathrm{~N}
$$

Fatigue life Equation for 2024-T3 Titanium 6AL-4V alloy

$$
\mathrm{S}_{\text {eq }}=\mathrm{S}_{\max }(1-\mathrm{R})^{0.62}
$$

Fatigue life Equation for 15-5PH (H1025) Stainless steel

$$
\log N_{f}=8.72-2.56 \log \left(S_{\max }-34.9\right)
$$

$\log N_{f}=11.75-4.45 \log \left(S_{\text {eq- }}-15.0\right)$

\section{RESULTS AND DISCUSSION}

\begin{tabular}{|c|c|c|c|c|c|c|c|c|}
\hline \multirow{3}{*}{ Materials } & \multirow{3}{*}{ Load Case } & \multirow[b]{2}{*}{ Displacemet } & \multicolumn{5}{|c|}{ Stress } & \multirow{3}{*}{$\begin{array}{l}\text { High Cycle } \\
\text { Fatigue (N) }\end{array}$} \\
\hline & & & $\begin{array}{l}\text { Von- } \\
\text { mises } \\
\text { stress }\end{array}$ & $\begin{array}{c}\text { Max } \\
\text { Principal } \\
\text { stress }\end{array}$ & $\begin{array}{c}\text { Min } \\
\text { Principal } \\
\text { stress }\end{array}$ & $\begin{array}{c}\text { Max } \\
\text { Stress } \\
\text { (Smax) }\end{array}$ & Seq & \\
\hline & & $(\mathrm{mm})$ & (Mpa) & (Mpa) & (Mpa) & (Mpa) & (Mpa) & \\
\hline \multirow{3}{*}{ Aluminum } & Vertical & 0.01 & 22.50 & 30.50 & 5.85 & 30.50 & 28.75 & $4.83 \mathrm{E}+11$ \\
\hline & Horizontal & 0.08 & 15.10 & 2.79 & -7.64 & 15.10 & 14.23 & $2.13 \mathrm{E}+15$ \\
\hline & Angle_42 & 0.05 & 12.10 & 11.90 & -0.09 & 12.10 & 11.41 & $3.53 \mathrm{E}+13$ \\
\hline \multirow{3}{*}{ Steel } & Vertical & 0.03 & 22.50 & 30.50 & 5.85 & 30.50 & - & $1.18 \mathrm{E}+12$ \\
\hline & Horizontal & 0.03 & 15.10 & 1.29 & -9.15 & 15.10 & - & $2.51 \mathrm{E}+10$ \\
\hline & Angle_42 & 0.02 & 12.10 & 11.90 & 0.01 & 12.10 & - & $1.75 \mathrm{E}+10$ \\
\hline \multirow{3}{*}{ Titanium } & Vertical & 0.07 & 22.10 & 32.60 & 8.12 & 32.60 & 30.54 & $2.81 \mathrm{E}+11$ \\
\hline & Horizontal & 0.05 & 14.80 & 2.50 & -7.66 & 14.80 & 13.86 & $3.19 \mathrm{E}+16$ \\
\hline & Angle_42 & 0.03 & 12.10 & 12.10 & 0.27 & 12.10 & 11.33 & $1.74 \mathrm{E}+14$ \\
\hline
\end{tabular}

\section{Analysed Results}

Convergence study for different material for original engine bracket.

\begin{tabular}{|c|c|c|c|c|c|c|c|c|}
\hline \multirow{3}{*}{ Materials } & \multirow{3}{*}{ Load Case } & \multirow[b]{2}{*}{ Displacement } & \multicolumn{5}{|c|}{ Stress } & \multirow{3}{*}{$\begin{array}{l}\text { High Cycle } \\
\text { Fatigue (N) }\end{array}$} \\
\hline & & & $\begin{array}{l}\text { Von- } \\
\text { mises } \\
\text { stress }\end{array}$ & $\begin{array}{c}\text { Max } \\
\text { Principal } \\
\text { stress }\end{array}$ & $\begin{array}{c}\text { Min } \\
\text { Principal } \\
\text { stress }\end{array}$ & $\begin{array}{c}\text { Maximum } \\
\text { Stress } \\
\text { (Smax) }\end{array}$ & Seq & \\
\hline & & $(\mathrm{mm})$ & (Mpa) & (Mpa) & (Mpa) & (Mpa) & (Mpa) & \\
\hline \multirow{3}{*}{ Aluminum } & Vertical & 0.67 & 389.00 & 530.00 & 107.00 & 530.00 & 499.63 & $2.77 \mathrm{E}+05$ \\
\hline & Horizontal & 0.49 & 226.00 & 294.00 & 46.60 & 294.00 & 277.16 & $3.19 \mathrm{E}+06$ \\
\hline & Angle_42 & 0.30 & 175.00 & 241.00 & 52.50 & 241.00 & 227.19 & $7.40 \mathrm{E}+06$ \\
\hline \multirow{3}{*}{ Steel } & Vertical & 0.22 & 389.00 & 530.00 & 107.00 & 530.00 & - & $6.63 \mathrm{E}+06$ \\
\hline & Horizontal & 0.16 & 226.00 & 294.00 & 46.60 & 294.00 & - & $3.48 \mathrm{E}+07$ \\
\hline & Angle_42 & 0.10 & 175.00 & 241.00 & 52.50 & 241.00 & - & $6.25 \mathrm{E}+07$ \\
\hline \multirow{3}{*}{ Titanium } & Vertical & 0.43 & 376.00 & 561.00 & 149.00 & 561.00 & 525.52 & $5.00 \mathrm{E}+04$ \\
\hline & Horizontal & 0.32 & 218.00 & 313.00 & 71.10 & 313.00 & 293.21 & $7.46 \mathrm{E}+05$ \\
\hline & Angle_42 & 0.19 & 173.00 & 256.00 & 71.40 & 256.00 & 239.81 & $1.92 \mathrm{E}+06$ \\
\hline
\end{tabular}

Table 8 : Analysed results of original engine bracket

Convergence study for different material for optimized engine bracke

Table 9 : Analysed results of optimized engine bracket

The above tables show the summary of the results for engine mounting Bracket for the various materials, and the observed results are within the allowable limits. Hence the design is safe. 


\section{Graphs}

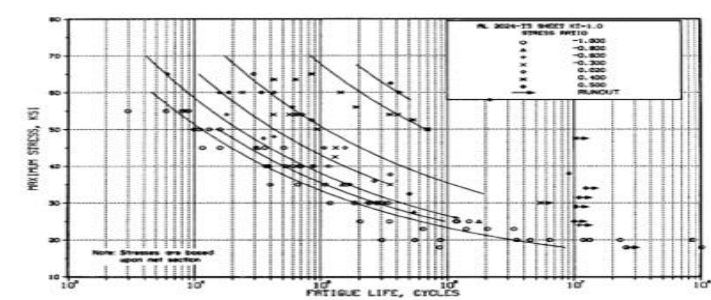

Graph: S-NCurve for 2024-T3 Aluminum alloy

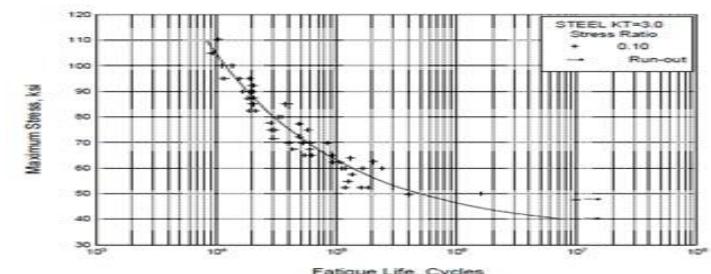

Graph : S-N Curve 15-5PH (H1025) Stainless steel

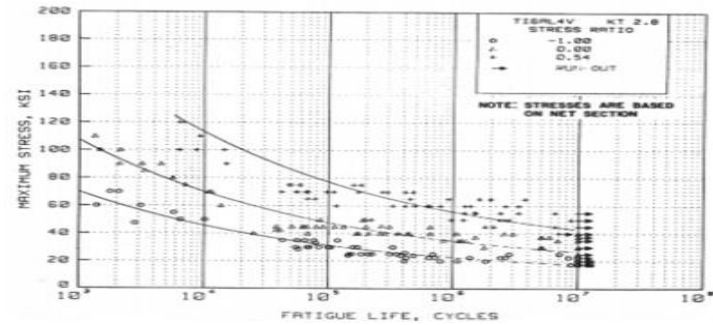

Graph : S-N Curve for Titanium 6AL-4V

\section{CONCLUSION}

The engine mount bracket is key important structural member in order to proper functioning of the engine. Various analyses carried out on the mounting bracket to check its strength and stability for different loadings comes from engine and supporting structure. The study was done using various materials which are 2024-T3 Aluminum alloy, Titanium 6AL-4V and 15-5PH (H1025) Stainless Steel. Objective is to study the strength and fatigue life of the bracket with geometry and material change. Based on the study and analysis, in three load cases (Vertical, Horizontal and Angle of 420 from vertical) with three materials the life of bracket is $>105$ cycles. By comparing of mechanical properties, cost and applications, Aluminum is better than all other two materials. In future studies I am planning to produce my final optimized model and conduct live experiments to understand the quality and stability of the bracket.As we know that engine components must made up of most heat resistant metals as it create more temperature. I am extending this study for thermostructural analysis future used case.

\section{REFERENCES}

[1]. The original 3D model of engine bracket is taken from https:/grabcad.com/challenges/ge-jetengine-bracket-challenge. Posted on June 11, 2013.

[2]. Aircraft structures for engineering students Fourth Edition by T. H. G. Megson.

[3]. Aircraft Structures by David J. Peery, Ph.D. J. J. Azar Ph.D. McGraw Hill Book Company 1982.

[4]. Airframe Stress Analysis and Sizing Second Edition by MICHAEL C. Y. NIU. 2001.

[5]. Airframe Structural Design by MICHAEL CHUN-YUNG NIU Lockheed Aeronautical Company Burbank, California 1989.

[6]. Analysis and Design of Flight Vehicles Structures, Bruhn

[7]. Fundamentals of Metal Fatigue Analysis by A. Bannantine, Ph.D. J. Comer, Ph.D. L. Handrock, $\mathrm{Ph} . \mathrm{D}$. University of lllinois.

[8]. Practical Finite Element Analysis First editionFiniteti Infinite, Pune book by nitin $\mathrm{S}$ Gokhale, sanjay S Deshpande, Sanjeev Bedekar, Anand N Thite.

[9]. MSC Patran, Nastran Software for analysis. [10]. CATIA V5 for Design optimization.

Cite this article as : Nerannagari Maruthi, C. Mohan Naidu , "Fatigue Life Prediction of Aircraft Engine Bracket", International Journal of Scientific Research in Science and Technology (IJSRST), Online ISSN : 2395-602X, Print ISSN : 2395-6011, Volume 6 Issue 2, pp. 151-171, March-April 2019. Available at doi : https://doi.org/10.32628/IJSRST196225 Journal URL : http://ijsrst.com/IJSRST196225 